\title{
My Call To Fellow Surgeons: 'the Scalpel Wielding Soldiers' Committed to Console and Cure!
}

\section{G. Siddesh ${ }^{1,2}$}

Accepted: 19 January 2022 / Published online: 9 February 2022

(c) Association of Surgeons of India 2022

\section{Happy New Year to you all!}

Hoping to see a world free from the pandemic soon! It has been 2 long years of Covid, filled with anxiety, chaos, and uncertainty. Every soul on earth has been affected by this pandemic directly or indirectly. But the trials faced by doctors are of a different world! Doctors had to safeguard society against a somewhat clueless enemy while saving themselves. Many of our fraternity suffered from severe Covid, and some succumbed to the pandemic. Surgeons in particular were hit badly as they had to work in closed confinement for long hours. The ever-changing surgical protocols had to be adhered to. The 'surgical training' also took a serious blow. The postgraduate students had to cater to Covid cases instead of following their regular surgical curriculum in their efforts to help the country to tide over a crisis, which was indeed the need of the hour. A limited number of surgeons had to manage a surge of surgical case load. We were overburdened physically and psychologically; financial and emotional stress drained us. However, we are in a better state of preparedness today than we were 2 years ago, with most of the population either vaccinated or naturally exposed to the virus. The response of the Indian government in containing the virus, mobilising resources, stepping up of facilities to meet a soaring demand within a short period of time ensured that our countrymen did not suffer as much as other countries with similar demography. The ongoing mammoth vaccine drive exhibits the resolve and commitment of our government to control the epidemic and reduce it to a low endemic entity. However, the danger is not fully over yet. We are now in the midst of a third wave caused by a new variant $O$-micron.

\section{G. Siddesh}

drgsiddesh@yahoo.co.in

1 Association of Surgeons of India - ASI, Mysuru, India

2 Consultant Endoscopist and Laparoscopic Surgeon, Medical Director, Sigma Hospital, Mysuru, India

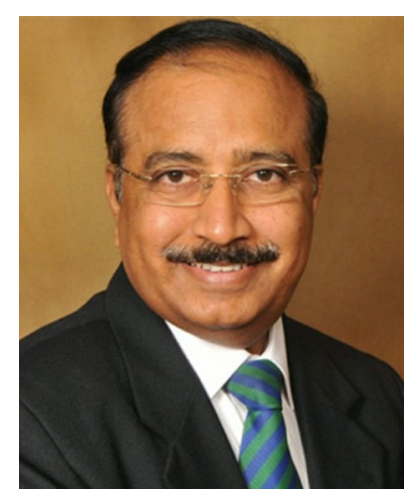

At this juncture, it is equally important to take adequate preventive measures to protect the specialised and skilled staff from getting exposed. For this, we need, an already delayed, large base of fresh recruitments and train them to meet the demands of frontline workforce. Tactical planning and judicious use of manpower are the key. Exposing the smallest possible group of specialists in performing elective surgeries and allowing them to work in batches will prevent infection of a large group at any point of time. Postponement of elective surgical procedures was instituted as a protocol by the central government early in the first wave, which was apt. But this was not a viable solution as the pandemic extended beyond 2 years.

Postgraduate residents are the major workforce in healthcare delivery system in any country. Every year, in India, more than 30,000 new residents join training programmes under various specialities. Unfortunately, this year, the admission process has been delayed by nearly 1 year due to administrative and legal hurdles. This needs to be addressed at the earliest as we are amidst 3rd Covid wave. The delay in postgraduate admissions has further deranged the training programmes of senior residents who have been relentlessly working on Covid frontline duties. The government needs to address this and the resulting cascading effects without delay. 
In the last 2 years, the surgical training has taken a heavy beating; the process of imparting both the basic as well as advanced skills to surgical trainees has suffered. There is an urgent need for skill-based training programmes for both residents and junior specialists. Surgical skill, as we all know, has to happen in stages, namely:

1. Learning by observation

2. Learning by assisting

3. Performing under supervision

And finally,

4. Performing independently

Surgical training is unique and cannot be fully addressed by the regular virtual training programmes which have efficiently replaced traditional teaching in other fields. We need to explore alternative methods of imparting surgical skills like:

1. Virtual, simulation-based training

2. Training using cadaveric labs

The Association of Surgeons of India, governed by the esteemed Executive Committee, has done an exemplary job in this direction under the leadership of past presidents, and the Director of the Academic Council. We, the present body, will continue the good work. Dr Santhosh John Abraham and his team are already on the task. The much awaited National Skill Enhancement Programme (NSEP) will begin in the first week of February 2022. This programme has gained popularity among the surgical community of India as well as international participants. The input-based format and innovative methods adapted by the NSEP will surely meet the aspirations of trainees.

Before I conclude, I remind you of Darwin's theory of evolution where he stated: 'survival of the fittest'. By 'fittest', Darwin did not mean the strongest, but the 'most adapted'. A surgeon is said to possess the heart of a lion, eagle's eyes, and fingers as dexterous as a lady's. The changing times require us to acquire the virtues of patience, perseverance, and calmness!

Once again wishing you all a very Happy New Year and year full of hope and fulfilment.

Dr. G Siddesh

Professor of Surgery

President Association of Surgeons of India - ASI

Mysuru India

Publisher's Note Springer Nature remains neutral with regard to jurisdictional claims in published maps and institutional affiliations. 